Fourth International Conference on Sustainable Construction Materials and Technologies http://www.claisse.info/Proceedings.htm

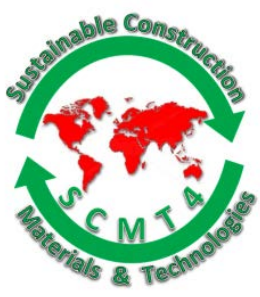

\title{
Influence of Surface Electrical Properties of C-S-H on Chloride Binding in Slag-Blended Cementitious Materials
}

\author{
Elakeswaran Yogarajah $^{1 a}$, Toyoharu Nawa ${ }^{1 b}$, and Kiyofumi Kurumisawa ${ }^{1 c}$ \\ ${ }^{1}$ Division of Sustainable Resources Engineering, Hokkaido University, JAPAN. \\ ${ }^{1 a}$ Email: <elakneswaran@eng.hokudai.ac.jp>, ${ }^{1 b}$ Email: <nawa@eng.hokudai.ac.jp>, \\ ${ }^{1 c}$ Email: <kurumi@eng.hokudai.ac.jp>.
}

\begin{abstract}
Knowledge on interface characteristics of $\mathrm{C}-\mathrm{S}-\mathrm{H}$ is important to understand the adsorption and transport behavior of ionic species into cementitious materials. In this study, the surface electrical properties of C$\mathrm{S}-\mathrm{H}$ and their influence on ionic adsorption have been investigated to be able to predict chloride binding on slag containing materials. The experimental data showed that the surface charge or electrokinetic potential of slag cement paste (SCP) are intermediate between Portland cement paste and $\mathrm{C}-\mathrm{S}-\mathrm{H}$ with $\mathrm{Ca} / \mathrm{Si}$ of 1.0. The surface site density of the $\mathrm{C}-\mathrm{S}-\mathrm{H}$ and the associated equilibrium constant value for dissociation are derived from potentiometric titration experiment and a surface complexation model. Further, the surface complexation modelling parameter for chloride adsorption on $\mathrm{C}-\mathrm{S}-\mathrm{H}$ with $\mathrm{Ca} / \mathrm{Si}$ of 1.0 were estimated by fitting the experimental data to simulation results. The estimated parameters for $\mathrm{C}-\mathrm{S}-\mathrm{H}$ together with surface complexation modelling parameters for Portland cement, which was derived and verified in a previous study, were used to predict the chloride binding on SCP. A batch experiment was performed to determine the total binding of chloride on SCP. It is considered that total binding of chloride is the amount of adsorbed chloride on the $\mathrm{C}-\mathrm{S}-\mathrm{H}$ surface as well as the chemical binding of chloride as Friedel's salt. The simulation results on chloride binding show good agreement with experimental data, follows a Freundlich isotherm. When Portland cement is partially replaced by slag, it modifies the surface electrical properties of $\mathrm{C}-\mathrm{S}-\mathrm{H}$ in addition to mineralogy and pore structure and leads to change in the chloride binding behavior.
\end{abstract}

\section{INTRODUCTION}

Corrosion of the reinforcing steel is the cause of the most serious durability problems in reinforced concrete structures exposed to seawater and de-icing salt [Malhorta, 2000]. Research has indicated that concrete made with ground granulated blast furnace slag (GGBFS) shows better performance than Portland cement concrete especially to resist chloride-induced corrosion [Song and Saraswathy,2006]. It is known that wellcured slag containing materials has a lower chloride diffusion coefficient and higher binding capacity. The main hydration product of cementitious materials called calcium-silicate-hydrate $(\mathrm{C}-\mathrm{S}-\mathrm{H})$ is an important phase to consider in the characterization of cementitious materials. Though generally considered an amorphous phase, $\mathrm{C}-\mathrm{S}-\mathrm{H}$ is widely accepted to have a layered crystal structure with many similarities to $1.4 \mathrm{~nm}$ tobermorite and jennite [Richardson, 2008]. The disordered stacked layers of C-S-H create a large volume of micro pores, with a resulting large specific surface area available for adsorption of significant amounts of ions. 
The titration and surface properties of $\mathrm{C}-\mathrm{S}-\mathrm{H}$ are not well characterized than other hydrous oxide phases, and only a few studies have reported on the surface functional groups of C-S-H [Chen, et al., 2004; Heath, et al., 1996; Pointeau I, et al., 2001; Viallis - Terrisse, et al., 2001; Yu et al., 1999]. The Viallis-Terrise et al., 2001 model for $\mathrm{C}-\mathrm{S}-\mathrm{H}$ considers that the surface of $\mathrm{C}-\mathrm{S}-\mathrm{H}$ consists of only one type of site termed the silanol site $(\equiv \mathrm{SiOH})$, and its density equals to 4.878 sites $/ \mathrm{nm}^{2}$. Pointeau et al., 2001 proposed that $\mathrm{C}-\mathrm{S}-\mathrm{H}$ consists of two kinds of surface sites for cesium adsorption and their densities were obtained by fitting the experimental data to the model results. The findings in that study show that the number of one-type site is a fixed average value, 10 sites $/ \mathrm{nm}^{2}$, irrespective of the calcium to silica $(\mathrm{Ca} / \mathrm{Si})$ ratios of the $\mathrm{C}-\mathrm{S}-\mathrm{H}$, but the other site postulated for the model depends on the $\mathrm{Ca} / \mathrm{Si}$ of the $\mathrm{C}-\mathrm{S}-\mathrm{H}$. The thermodynamic model in Heath et al. 1996 assumed that the surface of $\mathrm{C}-\mathrm{S}-\mathrm{H}$ is dominated by two kinds of sites: silanol and calcium ($\mathrm{CaOH}$ ) sites. Infrared spectroscopy shows that the presence of $\mathrm{Si}-\mathrm{OH}$ and $\mathrm{Ca}-\mathrm{OH}$ surface groups at the C$\mathrm{S}-\mathrm{H}$ surface depends on $\mathrm{Ca} / \mathrm{Si}$ ratio: $\mathrm{Si}-\mathrm{OH}$ groups at low $\mathrm{Ca} / \mathrm{Si}$ ratios and $\mathrm{Ca}-\mathrm{OH}$ groups present at high $\mathrm{Ca} / \mathrm{Si}$ ratios [Yu et al., 1999]. Solubility results have led to the interpretation that $1.4 \mathrm{~nm}$ tobermorite type $\mathrm{C}-\mathrm{S}-\mathrm{H}$ has large amounts of $\mathrm{Si}-\mathrm{OH}$ groups while jennite type $\mathrm{C}-\mathrm{S}-\mathrm{H}$ has many of $\mathrm{Ca}-\mathrm{OH}$ [Chen, et al., 2004]. These various results clearly show that more studies on the surface chemistry of C-S-H are essential to understand the characteristics at the $\mathrm{C}-\mathrm{S}-\mathrm{H} /$ solution interface to be able to describe ionic adsorption in cementitious materials.

It has been observed that the utilization of GGBFS as a partial replacement of cement has a significant influence on the chemistry of pore solution in cement systems [Andersson. et al., 1989; Elakneswaran, et al., 2009b]. The $\mathrm{pH}$ and the ionic strength of pore solutions are reduced with the addition of slag, and it will lead to changes the surface electrical properties at the cement hydrate/solution interface. The changes in the surface electrical properties will have a direct influence on the binding and diffusion characteristics of chloride. However, to the best knowledge of the authors, there is no model to predict the chloride binding and/or transport into cement blends with GGBFS considering the surface electrical properties of cement hydrates. Therefore, the purpose of this paper is to determine how the surface electrical properties of C-S$\mathrm{H}$ affect binding of chloride in slag cement paste. The research focuses on two parts: one is to determine the surface electrical properties of $\mathrm{C}-\mathrm{S}-\mathrm{H}$ and the other is to elucidate chloride adsorption mechanism in slag containing materials.

\section{EXPERIMENTAL INVESTIGATION}

Materials. C-S-H:1.0 (Calcium-Silicate-Hydrate gel with a Ca/Si ratio of 1.0) was synthesized by mixing $220.9 \mathrm{~g}$ of $\mathrm{Ca}(\mathrm{OH})_{2}, 179.1 \mathrm{~g}$ of AEROSIL200 $\left(\mathrm{SiO}_{2}\right)$, and $1200 \mathrm{ml}$ of $\mathrm{CO}_{2}$ free de-ionic water in an autoclave to achieve a $\mathrm{Ca} / \mathrm{Si}$ ratio of 1.0. The specific surface area of the $\mathrm{C}-\mathrm{S}-\mathrm{H}: 1.0$ was equal to $212 \mathrm{~m}^{2} / \mathrm{g}$ determined by multi-point $\mathrm{H}_{2} \mathrm{O}$ BET measurements. The synthesized $\mathrm{C}-\mathrm{S}-\mathrm{H}: 1.0$ gel was characterized by X-ray diffraction (XRD) and Fourier transform IR spectroscopy (FTIR). The slag cement paste (SCP) by mixing Ordinary Portland Cement (OPC) with 55\% of slag by weight and hardened cement paste (HCP) with pure OPC were prepared. Both SCP and HCP samples with water to binder ratio of 0.5 were cast and cured in saturated calcium hydroxide solution for 91 days.

Experiments. Potentiometric titration for $\mathrm{C}-\mathrm{S}-\mathrm{H}$ suspension $(0.25 \mathrm{~g}$ of $\mathrm{C}-\mathrm{S}-\mathrm{H}: 1.0$ in $50 \mathrm{ml}$ of $0.05 \mathrm{M}$ $\mathrm{NaNO}_{3}$ ) was conducted using an automated titration system. A blank solution was prepared at the same condition, without $\mathrm{C}-\mathrm{S}-\mathrm{H}$, to determine the initial hydroxyl concentration. Before the titration experiments, the $\mathrm{C}-\mathrm{S}-\mathrm{H}$ suspensions were equilibrated for two hours. Subsequently, the suspensions and blank were titrated with $1 \mathrm{M} \mathrm{NaOH}$ titrant between the initial $\mathrm{pH}$ of the suspension and $\mathrm{pH}$ 12.0. The $\mathrm{pH}$ electrode was calibrated with commercial buffer solution at $\mathrm{pH} 4.01,6.86$, and 10.01. The $\mathrm{C}-\mathrm{S}-\mathrm{H}$ is not stable in acidic conditions; therefore, the titration experiment was conducted only with $\mathrm{NaOH}$ titrant. The duration of the titration was around 90 minutes, and the suspensions were continuously stirred during the titration. Care 
was taken to minimize contamination from carbon dioxide. Desorption of protons on C-S-H was calculated by subtracting the remaining hydroxyl concentration in the suspension from that of the blank solutions.

A batch experiment was performed to determine the calcium adsorption on the $\mathrm{C}-\mathrm{S}-\mathrm{H}$ surface. For the calcium adsorption experiment, $0.1-10 \mathrm{mmol} / \mathrm{l} \mathrm{Ca}(\mathrm{OH})_{2}$ of solutions were added to $\mathrm{C}-\mathrm{S}-\mathrm{H}$ suspension $\left(0.05 \mathrm{~g}\right.$ of $\mathrm{C}-\mathrm{S}-\mathrm{H}: 1.0$ in $\left.10 \mathrm{ml} \mathrm{Ca}(\mathrm{OH})_{2}\right)$. The ionic strength and solid to liquid ratio were the same as used in the titration experiments, and $\mathrm{NaNO}_{3}$ salt was added to the suspension to maintain constant ionic strength. The C-S-H:1.0 suspension was equilibrated for 24 hours, after which the suspensions were filtered and the equilibrated $\mathrm{pH}$ was measured. The residual calcium concentration in the filtered solution was measured by inductively coupled plasma atomic emission spectrometry (ICP-AES). Another batch experiment was performed with chloride to determine the physical adsorption of chloride on the C-S-H surface. The chloride solutions with constant $5 \mathrm{mM} \mathrm{Ca}(\mathrm{OH})_{2}$ and varying chloride concentration $(0-100 \mathrm{ppm} \mathrm{NaCl})$ were prepared. Stock solutions were made in duplicate with one used as a blank and C-S-H:1.0 was added to the other. The suspensions ( $0.05 \mathrm{~g}$ of $\mathrm{C}-\mathrm{S}-\mathrm{H}: 1.0 \mathrm{in} 10 \mathrm{ml})$ were kept for 24 hours, and the concentration of chloride in the equilibrated solution was measured with ion-chromatography. The physical adsorption of chloride is the difference between the chloride concentration in the blank and in the $\mathrm{C}-\mathrm{S}-\mathrm{H}: 1.0$ suspension.

Zeta potential $(\zeta)$ measurements were carried out in $\mathrm{Ca}(\mathrm{OH})_{2}$ and $\mathrm{NaCl}$ solutions for $\mathrm{C}-\mathrm{S}-\mathrm{H}: 1.0$ and paste. Suspensions were prepared at $0.1 \mathrm{~g} / \mathrm{l}$ solid to liquid, and a Zetasizer Nano series apparatus was used to determine $\zeta$ with the Smoluchowski approximation.

A batch experiment was performed to determine the total binding of chloride on SCP. Around $25 \mathrm{~g}$ of SCP sample was immersed into known concentrations of sodium chloride solution for six months. Once the equilibrium is reached, the equilibrated chloride concentration was measured with ion-chromatography. The amount of bound chloride on SCP can be deduced from the difference between the initial and the final chloride concentrations in the solution.

\section{MODELLING APPROACH}

In this study, a geochemical transport code PHREEQC was used to perform all the calculations reported below [Parkhust and Appelo, 1999]. The speciation and sorption were calculated based on built-in models and thermodynamic data. The thermodynamic properties of minerals and aqueous species were collected from PHREEQC default thermodynamic database and CEMDATA07 [Lothenbach et al., 2008]. A generalized two-layer surface complexation model, which includes electrostatic interactions between adsorbing species and surface sites, built-in PHREEQC was applied to determine the surface site density of the $\mathrm{C}-\mathrm{S}-\mathrm{H}$ and the equilibrium constant values for dissociation surface sites as well as for adsorption of ions on its surface [Dzombak, et al., 1990].

Determination of surface electrical properties of C-S-H. The experimental surface charge density, $\sigma_{\exp }\left(\mathrm{C} / \mathrm{m}^{2}\right)$, can be determined from the difference in the total and free hydroxyl concentrations in the suspension through the equation given below [Mayant, et al., 2008]:

$$
\sigma_{\text {exp }}=\frac{F}{A S}\left(\frac{-[\mathrm{NaOH}] . V_{\mathrm{NaOH}, \text { add }}-\left\{\left[\mathrm{OH}^{-}\right]_{\text {init }}-\left[\mathrm{H}^{+}\right]_{\text {init }}\right\} . V_{\text {init }}}{V_{\text {init }}+V_{\text {NaOH.add }}}+\left[\mathrm{OH}^{-}\right]_{f i n}-\left[\mathrm{H}^{+}\right]_{\text {fin }}\right)
$$

where $F$ is the Faraday constant $(96,485 \mathrm{C} / \mathrm{mol}), A$ is the specific surface area $\left(\mathrm{m}^{2} / \mathrm{g}\right), S$ is the solid concentration $(\mathrm{g} / \mathrm{l}),[\mathrm{NaOH}]$ is the molar concentration of the titrant, $V_{\mathrm{NaOH} \text {,add }}$ and $V_{\text {init }}$ are the volumes of added $\mathrm{NaOH}$ and initial $\mathrm{NaNO}_{3}$ volume, and further $\left[\mathrm{OH}^{-}\right]_{\text {init }},\left[\mathrm{OH}^{-}\right]_{\text {fin }},\left[\mathrm{H}^{+}\right]_{\text {init }}$, and $\left[\mathrm{H}^{+}\right]_{\text {fin }}$ are the molar 
concentrations of $\mathrm{OH}^{-}$and $\mathrm{H}^{+}$derived from the measured $\mathrm{pH}$ of the initial and final solution considering $K_{w}$ and the activity coefficient of $\mathrm{H}^{+}$.

Eq. (1) considers the correction for dissolution as a high initial hydroxyl concentration in the suspension; therefore, Eq. (1) yields the relative surface charge density with the addition of $\mathrm{NaOH}$ titrant. The $\mathrm{pH}$ dependence of the surface charge can be modelled by acid-base equilibrium reactions with the associated constants. The generalized two-layer model, which is built-in PHREEQC, is used to model the experimental data. It is assumed that all surface complexes are inner-sphere complexes and background electrolyte ions such as $\mathrm{Na}^{+}$and $\mathrm{NO}_{3}{ }^{-}$are indifferent ions with respect to the $\mathrm{C}-\mathrm{S}-\mathrm{H}$ surface. Further, it can be assumed that the surface of $\mathrm{C}-\mathrm{S}-\mathrm{H}$ consists of only one type of site, which is here called the silanol site ( $\equiv \mathrm{SiOH}$ ). Considering the stability of $\mathrm{C}-\mathrm{S}-\mathrm{H}$, the titration experiment was conducted only at basic conditions; thus, protonation of the silanol sites can be considered negligible. The principal mechanism by which $\mathrm{C}-\mathrm{S}-\mathrm{H}$ acquires surface charge is the de-protonation of silanol sites as shown below [Elakneswaran, et al., 2009a; Viallis - Terrisse, et al., 2001].

$\equiv \mathrm{SiOH}+\mathrm{OH}^{-} \Leftrightarrow \equiv \mathrm{SiO}^{-}+\mathrm{H}_{2} \mathrm{O} K_{\mathrm{OH}}=\frac{a_{\mathrm{SiO}^{-}}}{a_{\mathrm{SiOH}} * a_{\mathrm{OH}^{-}}} \exp \left(-\frac{F \psi_{0}}{R T}\right)$

where $K_{O H}$ is the intrinsic equilibrium constant for de-protonation, $a_{i}$ is the activity of $i$ (solution species or surface species), $\psi_{0}$ is the surface potential $(\mathrm{V}), R$ is the universal gas constant equal to 8.31451 $\mathrm{J} /(\mathrm{mol} . \mathrm{K})$, and $T$ is the absolute temperature $(\mathrm{K})$. At high $\mathrm{pH}$, the cation adsorption is possible on the silanol sites but anion adsorption is limited. Thus, the negatively charged $\mathrm{C}-\mathrm{S}-\mathrm{H}$ particles are compensated by calcium ions in the solution, and the strong affinity of calcium ions to the surface causes the charge reversal. Calcium ions lose some of their water molecules and make an ionic bond with silanol sites through the reaction [Elakneswaran, et al., 2009a; Viallis - Terrisse, et al., 2001]:

$\equiv \mathrm{SiOH}+\mathrm{Ca}^{2+} \Leftrightarrow \equiv \mathrm{SiOCa}^{+}+H^{+} K_{\mathrm{Ca}}=\frac{a_{\mathrm{SiOCa}}{ }^{*} a_{\mathrm{H}^{+}}}{a_{\mathrm{SiOH}} * a_{\mathrm{Ca}^{2+}}} \exp \left(\frac{F \psi_{0}}{R T}\right)$

The dissociated silanol sites and adsorbed calcium cause the increase in surface charge density $\left(\sigma\left(\mathrm{C} / \mathrm{m}^{2}\right)\right)$ as:

$\sigma=\frac{F}{A S}\left[\left(\equiv \operatorname{SiOCa}^{+}\right)-\left(\equiv \mathrm{SiO}^{-}\right)\right]$

where $\left(\equiv \mathrm{SiOCa}^{+}\right)$and $\left(\equiv \mathrm{SiO}^{-}\right)$are the concentration of surface species (mol/l). According to GouyChapman theory (for a symmetrical electrolyte with valence $Z$ ), the surface charge-potential relationship is expressed as [Dzombak, et al., 1990; Parkhust and Appelo, 1999]:

$\sigma=\left(8000 \varepsilon \varepsilon_{0} R T \mu\right)^{\frac{1}{2}} \sinh \left(\frac{Z F \psi_{0}}{2 R T}\right)$

where $\varepsilon$ is the dielectric constant of water (dimensionless), $\varepsilon_{0}$ is the permittivity of free space $\left(8.854 * 10^{-}\right.$ $\left.{ }^{12} \mathrm{C} / \mathrm{V} . \mathrm{m}\right)$, and $\mu$ is the ionic strength.

The surface charge density, $\sigma\left(\mathrm{C} / \mathrm{m}^{2}\right)$, can be determined by solving Eqs. 2-5. The surface site density (number of $\equiv \mathrm{SiOH}$ groups per unit area) and two equilibrium constants $\left(p K_{O H}\right.$ and $p K_{C a}$ ) are determined 
by fitting the experimental data to the model results. The calculation procedure is given in the form of flowchart in Fig.1.

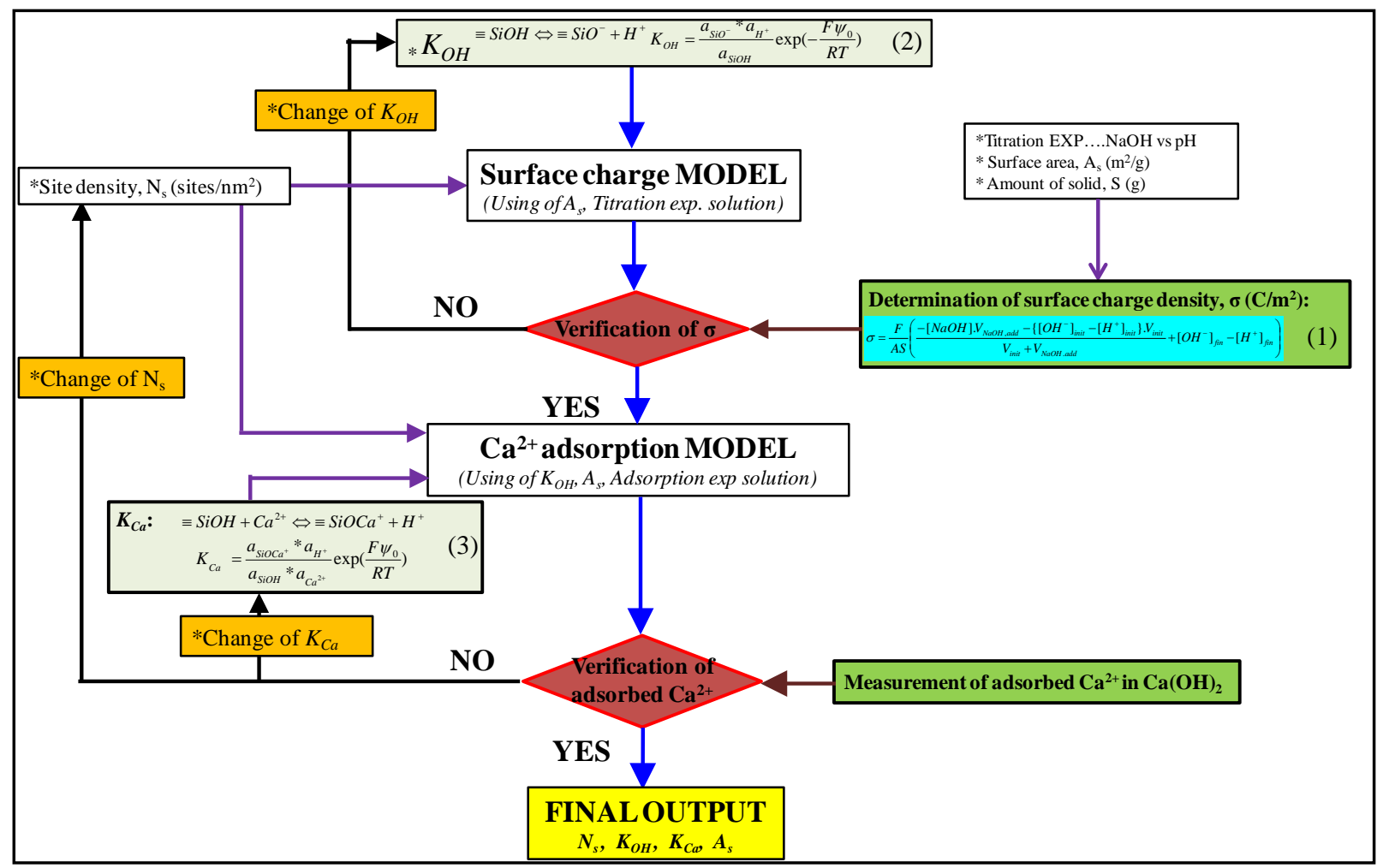

Figure 1. Flowchart to determine surface site density and the associated equilibrium constant values of $\mathbf{C}-\mathrm{S}-\mathbf{H}$

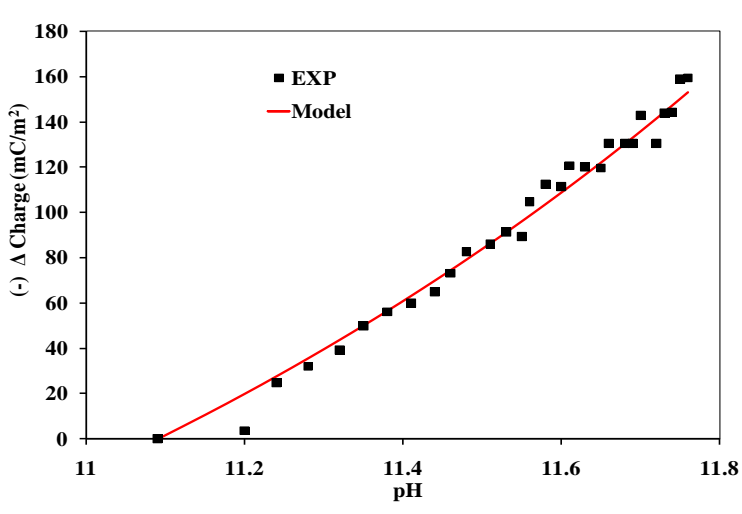

Figure 2. Measured and simulated relative surface charge densities of $\mathrm{C}-\mathrm{S}-\mathrm{H}$ as function of $\mathbf{p H}$

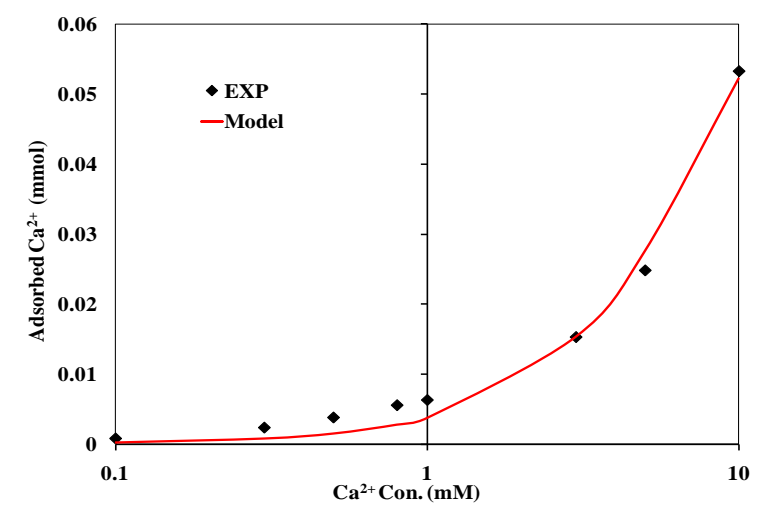

Figure 3. Measured and simulated adsorbed calcium on $\mathrm{C}-\mathrm{S}-\mathrm{H}$ as a function of the initial concentration of calcium

In the surface model, titration experiment can be simulated to determine the surface charge density with presumed values for the surface site density and $p K_{O H}$, and the measured specific surface area. The simulated surface charge density is compared with the calculated values (from Eq. (1)) from the experiment (Fig. 2). The $p K_{O H}$ is extracted by fitting the simulated relative surface charge density with experimental 
values. The calcium adsorption on C-S-H:1.0 is simulated for varying concentrations of calcium. The model uses the estimated $p K_{O H}$, the same site density and specific surface area, and the presumed $p K_{C a}$. Both surface site density and $p K_{C a}$ can be determined by fitting the simulated adsorbed calcium to experimental values (Fig. 3). The adjusted surface site density is used again to determine the surface charge density, and the new $p K_{O H}$ can be obtained by fitting. The simulations are repeated until to obtain the best fit between the simulated and experimental values. The estimated values for the surface site density, $p K_{O H}$, and $p K_{C a}$ are 10 sites $/ \mathrm{nm}^{2}, 9.34$, and 12.05 respectively. These values will be used to predict chloride adsorption on C-S-H:1.0 and also in SCP.

\section{RESULTS AND DISCUSSIONS}

\section{Surface characteristics of slag cement paste}

Increasing replacement ratios of slag reduces the $\mathrm{Ca} / \mathrm{Si}$ ratio of the $\mathrm{C}-\mathrm{S}-\mathrm{H}$ and this buffers the $\mathrm{pH}$ of the pore solution. Therefore, addition of slag makes it necessary to consider the effect on surface electrical properties of the $\mathrm{C}-\mathrm{S}-\mathrm{H}$. Once the portlandite is consumed by the pozzolanic reaction, the calcium concentration in the pore solution is reduced and this leads to a decrease in the net positive surface charge [Elakneswaran, et al., 2009b]. The electrostatic adsorptions of calcium and chloride ions on C-S-H and cement pastes are shown in Figs. 4 and 5 respectively. Here, the calcium adsorption compensates the negative surface and changes it to a positive surface at high concentrations of calcium while chloride adsorption causes an increase in the negative charge on the surface. These results are in agreement with the literature [Elakneswaran, et al., 2010; Heath, et al., 1996; Viallis - Terrisse, et al., 2001]. The hydration products of SCP are different those of the HCP and thus would show different surface electrical properties, resulting to a different adsorption phenomena. The electrostatic behaviour of SCP particles strongly depend on the properties of the added slag. The study here based on Figs. 4 and 5 shows the surface characteristics of SCP are intermediate between HCP and $\mathrm{C}-\mathrm{S}-\mathrm{H}: 1.0$. These findings will serve as a basis for the predictions of the adsorption and diffusion of ions in SCP.

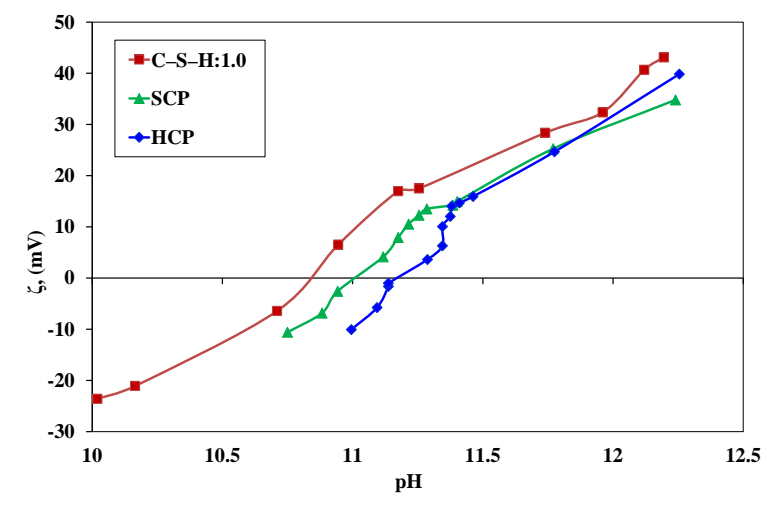

Figure 4. Measured zeta potentials of $\mathrm{C}-\mathrm{S}-$ $\mathrm{H}: 1.0$ and the various cement pastes in $\mathrm{Ca}(\mathrm{OH})_{2}$ solutions. The $\mathrm{pH}$ values represent the equilibrated $\mathrm{pH}$ of the suspensions.

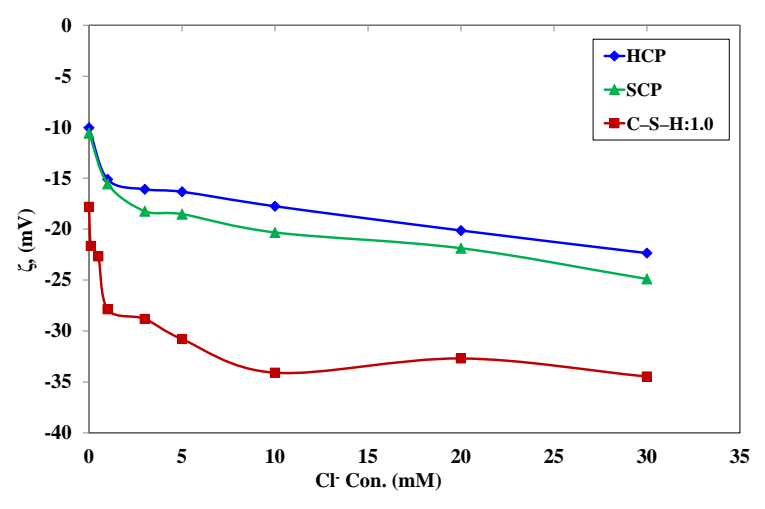

Figure 5. Measured zeta potentials of $\mathrm{C}-\mathrm{S}-$ $\mathrm{H}: 1.0$ and various cement pastes in $\mathrm{NaCl}$ solutions.

Prediction of chloride adsorption in slag cement paste. As shown in Fig.4, calcium ions influence both $\mathrm{pH}$ and the adsorption on suspended particles. The divalent calcium in the suspension neutralizes the negative surface of $\mathrm{C}-\mathrm{S}-\mathrm{H}$, and the surface charge of the particles becomes more positive at higher concentrations of calcium or high $\mathrm{pH}$ due to high concentration of calcium. The isoelectric point for $\mathrm{C}-\mathrm{S}-$ 
$\mathrm{H}: 1.0$ is around a $\mathrm{pH}$ of 10.85 or $0.4 \mathrm{mM}$ calcium. Therefore, C-S-H:1.0 surface particles are highly charged by calcium at higher calcium concentrations (concentrations higher than $0.4 \mathrm{mM}$ ). Chloride ions are able to adsorb on the calcium adsorbed $\mathrm{C}-\mathrm{S}-\mathrm{H}$ surface through inner-sphere complexation reactions [Elakneswaran, et al., 2009a; Hosokawa, et al., 2006]:

$$
\equiv \mathrm{SiOH}+\mathrm{Ca}^{2+}+\mathrm{Cl}^{-} \Leftrightarrow \equiv \mathrm{SiOCaCl}+\mathrm{H}^{+} \quad K_{\mathrm{CaCl}}=\frac{a_{\mathrm{SiOCaCl}} * a_{\mathrm{H}^{+}}}{a_{\mathrm{SiOH}} * a_{\mathrm{Ca}^{2+}} * a_{\mathrm{Cl}^{-}}} \exp \left(\frac{F \psi_{0}}{R T}\right)
$$

To further elucidate this, a two-layer surface complexation model was used to simulate chloride adsorption on the $\mathrm{C}-\mathrm{S}-\mathrm{H}: 1.0$ surface with adsorbed calcium. The model uses the surface complexation parameters that are estimated in Eqs. (2-3) with the new equilibrium constant from Eq. (6). The equilibrium constant value, $p K_{\mathrm{CaCl}}$, was derived by fitting the measured chloride adsorption data obtained in the experiments to the simulated results, the estimated $p K_{\mathrm{CaCl}}$ is equal to 8.23. Fig.6 shows the experimentally measured and simulated chloride adsorption on C-S-H:1.0 for a constant concentration of calcium $\left(5 \mathrm{mM} \mathrm{Ca}(\mathrm{OH})_{2}\right)$ with varying chloride concentrations.

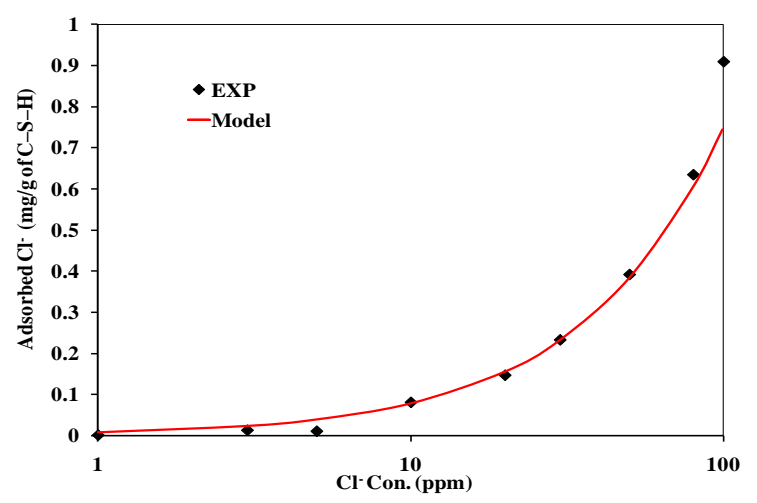

Figure 6. Measured and calculated adsorbed chloride on $\mathrm{C}-\mathrm{S}-\mathrm{H}: 1.0$ as a function of the initial concentration of chloride. The suspension has a constant calcium concentration ( $\left.5 \mathrm{mM} \mathrm{Ca}(\mathrm{OH})_{2}\right)$ with the chloride concentration varied.

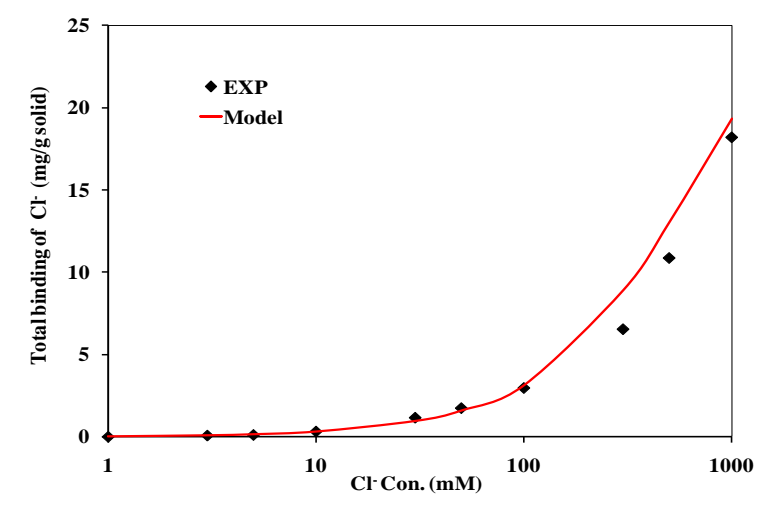

Figure 7. Measured and predicted total amounts of bound chloride on SCP.

It is recognized that a partial or complete replacement of $\mathrm{PC}$ with slag reduces the $\mathrm{Ca} / \mathrm{Si}$ ratio of $\mathrm{C}-\mathrm{S}-\mathrm{H}$ and also forms calcium aluminosilicate hydrate (C-A-S-H) [Richardson, 1992]. Aluminium can substitute silica in bridging and pairing positions of $\mathrm{C}-\mathrm{A}-\mathrm{S}-\mathrm{H}$ [Pardal, et al., 2012] and thus, it shows the existence of both silanol ( $=\mathrm{Si}-\mathrm{OH})$ and aluminol $(=\mathrm{Al}-\mathrm{OH})$ sites on $\mathrm{C}-\mathrm{A}-\mathrm{S}-\mathrm{H}$. Further, it can be hypothesized that the surface electrical properties of C-S-H in SCP display the properties in between C-S-H of HCP and CS-H:1.0 (Figs.4-5). From these, it can be considered that two kinds of surface sites are available on the CS-H of SCP for adsorption of ions. Although the detail investigation on the surface sites of SCP has not done in this study, it is assumed that one site in SCP is similar to the site on C-S-H of HCP while the other is similar to the site on C-S-H:1.0. The surface site density of C-S-H in HCP equals to $4.878 \mathrm{sites} / \mathrm{nm}^{2}$ [Elakneswaran, et al., 2009a; Viallis - Terrisse, et al., 2001], and the other surface complexation parameters for $\mathrm{C}-\mathrm{S}-\mathrm{H}$ in HCP such as the dissociation of silanol site and the adsorption of calcium and chloride are described elsewhere [Elakneswaran, et al., 2009a]. The surface site density and other surface complexation parameters that are necessary to model ionic adsorption for $\mathrm{C}-\mathrm{S}-\mathrm{H}$ : 1.0 are determined in here and detailed in the previous section. 
The two-site surface complexation model can be applied to predict the chloride-binding isotherm of SCP. Both cations and anions in the solution compete for the two types of binding sites, and the adsorption is considered as the surface complexation reactions at these sites. It is assumed that $\mathrm{C}-\mathrm{S}-\mathrm{H}$ dominates the physical adsorption of chloride in SCP, and there is none or a negligible amount of physical adsorption of chloride on other cement hydrates. Fig.7 shows the predicted and experimentally determined total binding of chloride on SCP. It is considered that total binding of chloride is the amount of adsorbed chloride on the C-S-H surface and the chemical combination of chloride in Friedel's salt. The chemical binding of chloride is calculated through the thermodynamic equilibrium reaction between monosulfoaluminate and chloride solution. There is a good correlation between the model predictions and the experimental data. The amount of bound chloride increases with concentration and follows a Freundlich isotherm. It can be inferred that the surface electrical properties of $\mathrm{C}-\mathrm{S}-\mathrm{H}$ in SCP represents a combination of $\mathrm{C}-\mathrm{S}-\mathrm{H}$ of HCP and C-S$\mathrm{H}: 1.0$. However, it does not provide details of the structure of the $\mathrm{C}-\mathrm{S}-\mathrm{H}$ of SCP or the relationship between the structures of the two kinds of $\mathrm{C}-\mathrm{S}-\mathrm{H}$. There is need for more laboratory studies and models to elucidate these in detail.

\section{CONCLUSION}

The interaction of ionic species with $\mathrm{C}-\mathrm{S}-\mathrm{H}$ was simulated through surface complexation reactions. The generalized two-layer model built-in PHREEQC was used to determine the surface site density of C-S-H and the associated equilibrium constant values for dissociation as well as for adsorption of ions. The zeta potential values for calcium and chloride adsorption on SCP are in between HCP and C-S-H:1.0 leads make an assumption that the surface electrical properties of $\mathrm{C}-\mathrm{S}-\mathrm{H}$ in SCP arise from a combination of the C-S-H of HCP and the C-S-H:1.0. The chloride binding on SCP was modelled with taking into account thermodynamic equilibrium reactions between cement hydrates and the solution and surface adsorption reactions. A good agreement was ascertained between the predicted and experimental binding of chloride, and the binding isotherm can be adequately described by the Freundlich equation.

\section{REFERENCES}

Andersson. K. et al., (1989) "Magnusson, Chemical composition of cement pore solution”, Cement and Concrete Research 19, 327-332.

Chen. J. J., et al., (2004) "Solubility and structure of calcium silicate hydrate", Cement and Concrete Research 34, 1499-1519.

Dzombak, D. A, et al., (1990) "Surface complexation modelling: Hydrous Ferric oxide”, A WileyInterscience Publication.

Elakneswaran, Y. et al. (2009a), Electrokinetic potential of hydrated cement in relation to adsorption of chlorides, Cement and Concrete Research 39, 340-344.

Elakneswaran, Y. et al. (2009b). Influence of surface charge on ingress of chloride ion in hardened paste, Materials and Structures 42, 83-93.

Elakneswaran, Y. et al. (2010), Ion-cement hydrate interactions govern multi-ionic transport model for cementitious materials, Cement and Concrete Research 40, 1756-1765.

Heath, T. G et al., (1996) "Thermodynamic modelling of the sorption of radioelements onto cementitious materials”, Material Research Society Symposium proceeding 412, 443-449.

Hosokawa Y. et al. (2006), "Models for chloride ion bindings in hardened cement paste using thermodynamic equilibrium calculations". In: J. Marchand et al., Editors, 2nd Int. Symp. On Advances in Concrete through Science and Engineering, RILEM Proceedings PRO vol. 51, RILEM Publications.

Lothenbach, B. et al. (2008). "Thermodynamic modelling of the effect of temperature on the hydration and porosity of Portland cement", Cement and Concrete Research, 38, 1-18.

Malhorta, V. M., (2000). "Durability of Concrete”, Corrosion Handbook Second Edition, R.W. Revie Ed., Wiley. 
Mayant, C et al., (2008). "Surface site density, silicic acid retention and transport properties of compacted magnetic powder", Physics and Chemistry of the Earth 33, 991- 999.

Pardal, X. et al., (2012). " ${ }^{27} \mathrm{Al}$ and ${ }^{29} \mathrm{Si}$ Solid - state NMR characterisation of calcium - aluminosilicatehydrate”, Inorganic Chemistry, 51, 1827-1836.

Parkhust, D. L. and Appelo, C. A. J., (1999). “A computer program for speciation, batch - reaction, onedimensional transport and inverse geochemical calculations”, USGS report.

Pointeau I, et al., (2001) “Cesium and Lead Uptake by C-S-H Phases of Hydrated Cement”. Mat. Res. Soc. Symp. Proceedings 663, 105-113.

Richardson. I. G., (2008) “The calcium silicate hydrates”, Cement and Concrete Research 38, 137-158.

Richardson, I. G. and Groves, G. W., (1992). "Microstructure and microanalysis of hardened cement pastes involving ground granulated blast-furnace slag”, J Mater Sci., 27, 6204-6212.

Song. H. W and Saraswathy. V., (2006). "Studies on the corrosion resistance of reinforced steel in concrete with ground granulated blast-furnace slag-An overview”, Journal of Hazardous Materials B 138, 226233.

Viallis - Terrisse, H. et al., (2001). "Zeta-potential study of calcium silicate hydrates interacting with alkaline cations”, Journal of Colloid and Interface Science 244, 58-65.

Yu. P. et al., (1999) "Structure of Calcium Silicate Hydrate (C-S-H): Near-, Mid-, and Far-Infrared Spectroscopy”, J. Am. Ceram. Soc. 82, 742-748. 